Revista Iberoamericana, Vol. LXXX, Núm. 247, Abril-Junio 2014, 535-551

\title{
DESENCANTOS EJEMPLARES: ESTÉTICA Y AFECTIVIDAD EN LA ESPAÑA DE LOS AÑOS NOVENTA
}

\author{
POR \\ Santiago Morales-Rivera \\ Universidad de California-Irvine
}

Recuerdo que de todos los niños de la pandilla del barrio yo era el único que tenía televisor y que ese día salí disparado del salón familiar y, bajando las escaleras de cuatro en cuatro, alcancé la calle y fui al bar donde jugábamos al futbolín y les grité a todos que habían matado a John Kennedy, lo grité varias veces muy exaltado, han matadoa Kennedy, han matado a Kennedy, y recuerdo que el jefe de la pandilla, tan impasible como siempre, me dijo: «iY?»

Enrique Vila-Matas, Hijos sin hijos (1993)

Si antes en España enseñaban a estudiar la historia de la literatura y de las ideas por generaciones (la Generación del 98, del 14, del 27, del 36, del 50), los maestros de ahora, claramente influidos por sus colegas anglosajones, tienden a explicarla por décadas. Este método de las décadas ha contribuido a paliar alguna deficiencia del método de las generaciones, como la tendencia criticada por José Carlos Mainer de buscar "homogeneidades intra-generacionales" ("El problema” 214). Sin embargo, como apunta el mismo Mainer en De posguerra, las décadas "acabaron convertidas como por arte de magia en eras” (109). Y esto es lo que sucedió tanto en las culturas anglosajonas como en las hispánicas con la década de los sesenta, por poner un caso espectacular, que fue la expresión titular de toda una época caracterizada, según escribe Gabriel Albiac en Mayo del 68, por "la apología de la subversión, el empeño innegociable de transformar el mundo y el rechazo de cualquier complicidad con los que mandan” (26). ${ }^{1}$

Con los años noventa, por otra parte, lleva camino de suceder lo mismo y convertirse también esta década en otra era. Los acontecimientos de 1989, el colapso de la Unión Soviética y del comunismo europeo junto al colapso en torno a ese mismo año de

1 Estas páginas son en buena medida la continuación, o la contraparte, de un breve ensayo que publiqué en ReVista (2008) con el título "Degeneration of the Sixties. A Look at Spain". 
varias dictaduras y revoluciones en América Latina, inauguran en Occidente “a postrevolutionary situation of near-anomy in which disenchantment is almost unavoidable" (Dahrendorf 12). Sendas épocas de utopía y desencanto, de arrebato y desconcierto, así como sus correspondientes décadas y fechas emblemáticas -el 68 y el 89-mantienen algo más que una inquietante relación especular de necesidad, que diría Claudio Magris. Ambas épocas han dado lugar, además, a una suerte de encrucijada entre el optimismo y el pesimismo que, en palabras de Raymond Carr, parece representar otro "caso clásico" de fin-de-siglo (Visiones 11): un punto privilegiado de observación del pasado durante el cual la idea de generación, así como nociones derivadas del tipo degeneración y/o regeneración, vuelven a adquirir un profundo interés crítico.

Las siguientes reflexiones tienen como objeto, primero, revisitar qué ha sucedido entre los noventas y los sesentas para que Occidente, en general, y España, en particular, experimenten dicha "situación anómica y profundamente desencantada” (Dahrendorf). Segundo, examinar cuáles son los vínculos y tensiones entre este desencanto o este desconcierto paradigmáticamente finisecular y cierto humorismo, como el que expresa, por poner por caso, la cita de Enrique Vila-Matas que encabeza este ensayo. Y tercero, reivindicar las lecciones (sentimentales, políticas, estéticas) que pueden extraerse de semejante forma cínica de interpelar el desconcierto de cara al presente siglo veintiuno. ${ }^{2}$

UNA ARQUEOLOGÍA DE LOS NOVENTA

A tenor del testimonio citado de Gabriel Albiac, así como del de Fernando Savater: “anhelo del Cuerpo Místico, en el que todos seremos uno” (Voluntad 302) ironiza éste último sobre los años 1960, aquella década prodigiosa de los sesenta fue realmente informada por la noción de generación; cuando menos si nos atenemos a la definición que dio José Ortega y Gasset: “Cada generación representa una cierta altitud vital, desde la cual se siente la existencia de una manera determinada” (79, énfasis del autor). Es más, dada la heterogeneidad entre lo que proponían los jóvenes de los sesenta y lo recibido de las generaciones precedentes, esa época acuñó con especial interés político la idea de generación.

2 La conexión entre los dos últimos fines de siglo ha sido señalada por Jürgen Kleist y, en el contexto español, por Raymond Carr y más recientemente por Antonio Francisco Pedrós-Gascón, entre otros. “The term 'fin de siècle' is most often used to describe the characteristics of art, literature, and society at the turn of the nineteenth century”, escribe Jürgen Kleist, "European culture, it seemed then, had come to an end: Empires were on the brink of collapse, societies were divided into a few wealthy and great number of poor people, and new technologies and inventions -like cinematography and the automobilewere changing the worldviews of all.... A hundred years and two World Wars later, humankind is again approaching the end of a century. As before, mighty empires have collapsed, the Balkans are in turmoil, the world is still divided into the rich and the poor, and new technologies and inventions change our world faster than ever" (ix).

Revista Iberoamericana, Vol. LXXX, Núm. 247, Abril-Junio 2014, 535-551 ISSN 0034-9631 (Impreso) ISSN 2154-4794 (Electrónico) 
Los sesenta fueron, ante todo, una cuestión generacional y constituyeron, además, un modelo de lo que el mismo Ortega llamó “épocas eliminatorias” (80). Por oposición a las "épocas cumulativas", en las que se da una homogeneidad entre lo recibido y lo propio, la de los sesenta sería, en palabras de este pensador, una "generación de combate.... que no trata de conservar y acumular, sino de arrumbar y sustituir, los viejos quedan barridos por los mozos” (81). Como sucede con toda generación, ésta instituyó su correspondiente fecha titular también -el archicitado 1968- puesto que en aquel año coincidieron las experiencias traumáticas o aglutinantes más determinantes de sus líneas de actividad: París, Tlatelolco, Praga, además de la dilatada guerra en Vietnam.

Debe sin embargo apostillarse que en España, que es el país en que quiero enfocarme aquí (aunque no por ello deban restringirse solo a España las siguientes reflexiones), aquel fenómeno generacional de los sixties no se correspondió exactamente con tales años. Occidente podía estar en los sesenta en plena transición hacia una nueva era "posindustrial”, “posestructuralista” y hasta "posmoderna”, cuando allende los Pirineos, como bien señala en contrapartida Ramón Buckley, "todavía no habíamos hecho nuestra transición, es decir, una transición hacia la democracia” (xi, énfasis del autor).

La sociedad española de los años sesenta, según el análisis de Raymond Carr, exhibía síntomas de una "modernización superficial” (Modern Spain 168). Hubo un espectacular desarrollo económico, especialmente en los sectores del turismo y de la industria, con el consecuente movimiento migratorio del campo a las ciudades. Atrás quedaba pues la autarquía substituida por una incipiente sociedad de consumo (Carr y Fusi 257). Como resultado de esta liberación económica, hubo considerables "reformas culturales y políticas" (Payne 414). Basadas sin embargo en "una producción populista de entretenimiento, la canción popular, los toros, el fútbol y la españolada de los sesenta”, estas reformas no representaron tanto una revuelta (al modo de Francia, por ejemplo) como un "espectacular proceso de desideologización estatal”, según Teresa Vilarós (“Cine y literatura” 195).

Y vinieron también con los sesenta, por supuesto, cambios en la literatura. "Sometime during the 1960s”, escribe Brad Epps, "the mirror breaks for Spanish narrative” (193). Obras de Luis Martín Santos, Juan Goytisolo, Miguel Delibes, Camilo José Cela y Juan Benet, "wreak havoc on the reality, idea, and ideal of realism", sostiene Epps, "[and] language turned into its own object becomes opaque, polyvalent, and at time even purposeless” (194). Con todo, estos escritores (excepto quizás Benet) adolecieron de un profundo "españolismo", por ejemplo, de una exclusiva preocupación por los problemas de España. Y a juzgar por Jo Labanyi, tal "Spanishness” los convierte en cómplices indirectos del franquismo en tanto el régimen "tried to unify the nation by projecting difference outside its borders in the form of otherness: la anti-España, necessarily equated with foreign influence" (397).

Lejos de inscribir, pues, un cambio radical con respecto al pasado, en España los años sesenta trajeron más bien una serie de “cambios” que, en opinión de Eduardo Subirats,

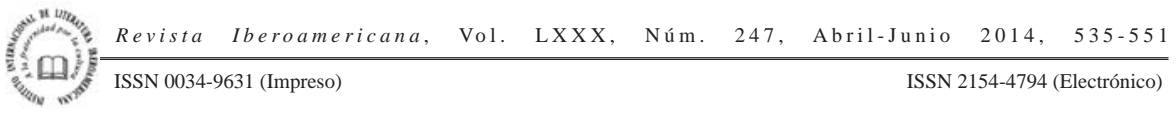


encerró múltiples “ambigüedades” (27). Entre la represión y la resistencia, la liberación y la circunspección, la inspiración extranjerizante y el lastre españolista, la sociedad y cultura españolas comenzaron a experimentar en los sesentas una metamorfosis que no termina de cuajar sin embargo hasta bien entrados los setenta, con la transición de la dictadura a la democracia, es decir, con el periodo en que se concretiza la confrontación del orden viejo de cosas con el nuevo.

La transición se erige así, demoradamente con respecto al resto de Occidente, como el episodio aglutinante en España del fenómeno generacional que había comenzado en el extranjero más de una década antes. De ahí que en la historia literaria y cultural española la llamada Generación del 68 sea en verdad la de autores que empiezan a publicar en los años setenta (como sucede en literatura con Manuel Vázquez Montalbán, Ana María Moix, Eduardo Mendoza, Juan José Millás, Soledad Puértolas y Muñoz Molina o en la canción de autor con Luis Eduardo Aute o Lluis Llach) y que, dependiendo del contexto y los antólogos, toma apelativos tan diversos como "generación perdida" (Albiac), "generación del fracaso" (Subirats), "generación de los novísimos” (Castellet) o "generación del 75”, entre otros.

Pues bien, llegadas las décadas de los ochenta y, sobre todo, la de los noventa, que es la que ahora nos ocupa, la gran ironía de aquella generación transicional es que, tratándose en principio de una "generación de combate”, propia según Ortega y Gasset de "épocas eliminatorias", parece haberse convertido en otra "generación cumulativa", típica de épocas de senectud y, lo que es más, representativa de la actitud vital más tradicionalmente española. Semejante decadencia o degeneración, conforme se acerca el fin de siglo, de algunos (por supuesto no todos) de aquellos jóvenes internacionalistas, no es su problema natural de senilidad, o no sólo. Sobre todo es un problema que concierne a la crítica, es decir, al modo en que en los noventa interpretamos y asumimos el legado de los sesenta. Trataré de explicarme.

\section{EL LEGADO DE LAS UTOPÍAS}

La verdadera "subversión" adentro de las generaciones sesentayochistas no se relacionó tanto con la restauración de la idea de utopía, sino con el fracaso de ésta. En París, el movimiento rebelde de Mayo del 68 fue traicionado, según Albiac, por los propios partidos de la izquierda. Para Savater, "[l]os arrebatos de mayo guardaban secretas complicidades con los tanques de agosto" (Voluntad 300), esto es, con la invasión soviética de la antigua Checoslovaquia. Y en España, el cambio utópico fue también, como poco, problemático. Cosa a la que contribuyeron el modo en que se realizó la transición -“Santa Transición” para unos, "Pactada Traición” para otros-y, sobre todo, el "trágico atraso" con que llegaba a España la utopía: "precisamente cuando la Historia prometía alcanzar su plenitud-en la democracia, quizás el socialismo-” escribe Buckley,

\footnotetext{
Revista Iberoamericana, Vol. LXXX, Núm. 247, Abril-Junio 2014, 535-551 ISSN 0034-9631 (Impreso) ISSN 2154-4794 (Electrónico)
} 
“resultaba ser que la Historia ‘no existía', que era una realidad 'ilusoria’ y que por tanto, tan ilusorio era el fascismo que habíamos padecido como la democracia o el socialismo que habían de llegar” (78).

A final de cuentas, de las utopías sesenteras va quedando en los noventa, por un lado, una clara sensación de extravío: “Si alguna herencia nos dejó el 68”, confiesa Albiac en 1993, “es la pérdida de los márgenes y de las referencias” (15); y, por el otro, de desconfianza: "La desconfianza hacia los órdenes creados, los ideales teológicos” escribe Savater (Voluntad 304). Y es precisamente este extravío, esta desconfianza, en suma, esta suerte de negatividad lo que constituye la "altitud vital” (que decía Ortega) de aquella generación de combate, su verdadera subversión: la confesión y denuncia -resumiría Albiac en clara referencia al revolucionario análisis foucaultiano del poder/ saber- de "un nuevo modelo de poder y de dominio, la difusión generalizada de la sumisión, a través de una red capilar que atraviesa cuerpos y conciencias de manera lo suficientemente tenue y universal como para no poder ser siquiera designable” (178).

Ahora bien, si además de “altitud vital” toda generación tiene también, siempre según Ortega y Gasset, una “misión histórica” (82), entonces la misión de aquella generación sesentayochista fue dejar a las generaciones posteriores, es decir, a las de las décadas de los ochenta y noventa, desheredadas: tal es el legado de las utopías y en ello reside su grandeza y su miseria, su mérito y su vergüenza frente las generaciones que les han sobrevenido. Las dejaron, según Albiac, "sin futuro. Sin sentido también. Y sin sujeto” (13). El espectacular estallido desde los setenta en adelante de las teorías de Lyotard, Baudrillard y Jameson responde a este supuesto agotamiento de la historia, del sentido y del sujeto. Condición en teoría posmoderna e internacional, que, como bien detecta Yaw Agawu-Kakraba, está al mismo tiempo íntimamente relacionada también con dos circunstancias “unmistakably Spanish”: “la movida” y "el desencanto” que sobrevino a la transición (2). ¿Qué más dejaron los años de la transición que, según lo escrito y de cómo se lean estos años transicionales, pueden extenderse hasta 1993?

En Demasiadas preguntas, una novela de 1994 sobre el relevo de poderes durante la transición, Dámaso Medina -un profesor anti-franquista que recuerda, por muchas razones que no podemos entrar aquí, al escritor Rafael Sánchez Ferlosio- confiesa mucho más: "por mantener bonita mi conciencia les he dejado [a mis hijos] sin nada: sin Dios, sin patria, sin amo, sin familia, sin esperanzas, y, sobre todo, sin un duro" (187). Inestimable legado, que, al final de esta novela de Félix de Azúa, autor de aquella generación perdida del 75, recibe Dalila, la hija de Dámaso. Según la describe el narrador, Dalila es una “viuda arcaica” (206) que en el transcurso de su juventud ha perdido a su novio (muerto por abandono de unos y otros, franquistas y demócratas, en los calabozos de las comisarías madrileñas), a su madre (fallecida en los sixties por sobredosis tras haberse fugado en una DKV con una pandilla de hippies), así como la única herencia crematística que podía haberle dejado su padre. Y es que al final de esta

Revista Iberoamericana, Vol. LXXX, Núm. 247, Abril-Junio 2014, 535-551 ISSN 0034-9631 (Impreso) ISSN 2154-4794 (Electrónico) 
suerte de esperpento de la transición el padre anti-franquista acaba desestimando también una bien remunerada oferta del Ministerio de Educación para escribir una Gramática del Español por la misma razón de "mantener bonita [su] conciencia”, o, como decía Albiac, desestima esta oferta ministerial por su "empeño innegociable de transformar el mundo y el rechazo de cualquier complicidad con los que mandan” (26).

Pero aún dejaron más tras su paso aquellos años utópicos. Si Albiac advierte que “del 68 es imposible hablar en primera persona” (13), ésta, y la forma impersonal, son las únicas formas de hablar que parecen quedar conforme se acerca el fin de siglo xx. Y es que por dejar no dejó aquella generación ni la idea de generación. De hecho, la única generación proclamada desde entonces dentro de la historia literaria se ha denominado, significativamente, generación $X$.

Sobre los narradores de esta Generación X, jóvenes que comienzan a escribir en los años noventa, la hispanista Carmen de Urioste hace un balance que parece corroborar, punto por punto, cada una de las aseveraciones hasta aquí expuestas acerca del legado de las utopías -y lo mismo puede decirse de las conclusiones que extraen Angeles Encinar, Kathleen M. Glenn (12 y ss.) y Dorothy Odartey-Wellington (23) sobre la novelística española del cambio de siglo xx a xxı. José Ángel Mañas, Ray Loriga, Lucía Etxebarría, Belén Gopegui o Juan Manuel de Prada, todos ellos escritores relacionados con la Generación X, y, en más de un caso, autores que se reconocerían a sí mismos en los personajes desheredados de Azúa, "parten en sus novelas de tramas argumentales casi inexistentes" (Urioste 458), substituyen "la focalización de los héroes problematizados por la de la sociedad sin rostro, impersonal” (461) y, por último y no menos importante, escribe de Urioste, ofrecen una realidad social cercana a la anomia. ${ }^{3}$

Tal sensación de pérdida, de extravío y anomia, tal estado de negatividad, de desconfianza y desubjetivización, o, en resumen, tal desahucio, que, conforme se acercó el fin de siglo, dejaron a su paso las utopías, representa-insisto- una inestimable lección cuyo alcance crítico quizás no estemos todavía, a estas alturas del nuevo milenio, en disposición de comprender. El problema viene, sin embargo, cuando transformamos este insondable desahucio de los noventas en lamentación, en queja y desencanto, en “identificación con la pérdida” que diría Freud (238), en definitiva: en melancolía. Es aquí donde las "generaciones de combate" pueden degenerar y convertirse en "cumulativas". Puesto que en lugar de barrer el pasado, más bien, y en un gesto tradicionalmente español, se identifican con él: "La transformación icónica de las imágenes de España”, lamenta por ejemplo Subirats, "no se ha detenido ante lo que en otro tiempo y en otro

\footnotetext{
3 Esta anomia social, como indica el historiador Juan Pablo Fusi, se hizo notar especialmente con los escándalos financieros, políticos y judiciales de los casos Banesto, GAL y Sogecable, así como con el no menos significativo retorno a la ética que reclamaron varios ensayos divulgativos, como Desde la perplejidad (1990) de Javier Muguerza, Ética para Amador (1991) de Fernando Savater, Aproximación a la ética (1992) de Nobert Bilbeny y Ética para náufragos (1993) de José Antonio Marina.
}

Revista Iberoamericana, Vol. LXXX, Núm. 247, Abril-Junio 2014, 535-551 
lugar pudiera haber sido el centro sagrado de una auténtica renovación de la realidad de España: su memoria histórica” (40-41, énfasis mío).

Ciertamente, de un revisionismo crítico -o de lo que Walter Benjamin llamaría una lectura a contrapelo- de la "memoria histórica" de España así como de otros países latinoamericanos con un pasado dictatorial también, ha aprendido toda una generación de hispanistas criados durante la democracia a no temer a hablar con los fantasmas, a reconocer cierta razón de los vencidos y, en última instancia, a ampliar el horizonte ético con el cual evaluar la experiencia histórica. ${ }^{4} \mathrm{Y}$ sin embargo, al filo del nuevo milenio, este revisionismo benjaminiano de la memoria histórica parece haber derivado hacia lo que el mismo Benjamin denominó una "melancolía de izquierdas". Esto es, parafraseando a Wendy Brown (170), en que terminemos más interesados en las pasiones y en las convicciones revolucionarias pasadas, que en el presente existente que queremos cambiar o revolucionar mediante esas mismas convicciones.

“Argumentos patéticos”, un controvertido artículo de Ángel Loureiro, argumenta acerca de estos últimos tratamientos de la memoria histórica: "De una historia mesiánica cargada de promesas de un futuro mejor hemos pasado a una visión de la historia como agravio" (22). Y esto es lo que parece suceder (y no dudo de que les sobren motivos) con Subirats, Albiac y otros pensadores progresistas: que han reemplazado el concepto de "historia mesiánica" por el de "historia como agravio". Con el resultado, además, de que el carismático altruismo sesentero se ha visto substituido durante los años noventa por el ensimismamiento, y, en ocasiones, por el narcisismo también. ¿Cómo es posible si no, que la época más reacia a perpetuar la tradición -jaquellos sesentas!- sea durante el cambio de siglo la época que más retrospectivas suscita, a la que más se vuelve, incluso la que más nos ata al pasado? Por poner un caso rotundamente actual, ante las recientes movilizaciones juveniles del llamado 15-M (15 de mayo) en múltiples ciudades de España, algunos analistas no paran de buscar vínculos con el Mayo del 68, por más que ambos movimientos sean bien distintos. ¿Acaso no puede ser "revolucionario" el 15-M por sí mismo y aparte del precedente francés? Algo debe de estar fallando con los modos de interpretar el legado de aquella era utópica de los sesentas de cara al presente siglo.

\section{A vueltas Con el Desencanto, o, Del MAl DE Siglo (VEINTE)}

Dicha degeneración a partir de los noventa del espíritu utópico de los sesenta afecta de manera especial a uno de los debates más controvertidos dentro del hispanismo: el debate en torno al desencanto. A comienzos del siglo xxi Nelly Richard detecta "un estado de melancolización del pensamiento" ("Reconfiguraciones” 288) en varios países

4 Prueba de ello es la amplia bibliografía revisionista de la guerra civil y del franquismo que desde ambos lados del espectro político ha complementado o suplementado la ya existente visión crítica de la historia, a juzgar por Santos Juliá y José Carlos Mainer, en la historiografía y la literatura previa a la transición.

Revista Iberoamericana, Vol. LXXX, Núm. 247, Abril-Junio 2014, $535-551$
ISSN 2154-4794 (Electrónico) 
hispánicos con un pasado de dictadura militar. Tal melancolización del pensamiento obedece a "un golpe", "una pérdida de sentido" o "una falla que no puede acomodar ninguna reparación de saber", escribe Richard (290) haciéndose eco de las reflexiones de Alberto Moreiras e Idelber Avelar sobre las llamadas posdictaduras en Latinoamérica. En España, la crítica cultural de la transición está informada por la omnipresente noción de desencanto. Al filo del nuevo milenio, Teresa Vilarós(1998) y Alberto Medina(2001), entre otros, denuncian la "pérdida de sentido" o la crisis abierta por los "pactos" transicionales interpretándola, respectivamente, en términos de "desencanto" y "melancolía” así como de otras acepciones más o menos coloquiales de la melancolía -por ejemplo, de la identificación con el pasado franquista- como "mono", "cuelgue” y "enganche".

Este "nuevo paradigma melancólico" (Medina 54) encierra, sin lugar a dudas, una lectura a contrapelo de cómo se realizó (o no) la transición de la dictadura a la democracia. Y sin embargo, es al mismo tiempo representativo también de la actitud vital más tradicionalmente española. Si Medina reconoce que "las razones" del nuevo paradigma melancólico en España "van más allá de la herencia histórica” (54) del franquismo, ese gran conocedor de la historia cultural de la melancolía que es Roger Bartra sienta como precedente de la melancolía "posmoderna" de nuestros días "el inmenso sol negro de la melancolía española de los Siglos de Oro" (14). Dentro de tan larga tradición melancólica, la crítica posdictatorial de Subirats, Moreiras, Richard, Avelar, Vilarós y Medina representaría también otra confusa forma en que se manifiesta u oculta "ese intrigante", según el propio Bartra, "misterio español” de la melancolía (15). Veamos por qué.

Más inmediato que los Siglos de Oro, el Fin de Siglo xix es un precedente histórico sumamente pertinente a efectos de rastrear las "razones" de este paradigma melancólico de fines del siglo xx. Recuérdese los ríos de tinta, asimismo atrabilaria, que produjo dentro de España el desastre del 1898, la crisis de la razón y la fe, la confusión de los límites entre el campo y la ciudad o entre el pasado y el presente, así como las disquisiciones durante ese mismo cambio de siglo xIx a xx entre el europeismo y el españolismo, el españolismo y los regionalismos, lo público o lo social o lo democrático, por un lado, y lo íntimo, lo individual e incluso lo anárquico, por el otro. Todo ello disyuntivas y circunstancias finiseculares decimonónicas en muchos sentidos distintas a las que informan la crítica del desencanto de este otro fin de siglo, pero, al mismo tiempo, inquietantemente afines también.

Ambos fines de siglo están atravesados por lo que Ricardo Gutiérrez Mouat denomina "un regionalismo trasatlántico" (136). Bajo el rubro posdictaduras, cien años después del 98 vuelven a conectarse la historia política de España y la de varios países latinoamericanos del Cono Sur que han sufrido dictaduras militares también, como Argentina, Brasil, Chile o Paraguay. Dadas las particularidades, los matices, incluso las contradicciones entre las historias políticas de cada uno de estos países, el sesgo

\footnotetext{
Revista Iberoamericana, Vol. LXXX, Núm. 247, Abril-Junio 2014, 535-551 ISSN 0034-9631 (Impreso) ISSN 2154-4794 (Electrónico)
} 
topográfico este/oeste, apostilla Gutiérrez Mouat, no tendría por qué obedecer a ninguna necesidad general de fondo: interpretar la historia política española contemporánea visà-vis la de los países latinoamericanos mencionados es "una opción [metodológica] entre otras” (148). Y sin embargo, los vínculos entre España y ultramar a fines de siglo XIX también bajo el mismo sol negro de la melancolía sientan un importante precedente de esta otra adopción, a fines de siglo xx nuevamente, del método trasatlántico. Este último regionalismo trasatlántico en clave posdictatorial sí puede venir en tal caso determinado, si no por una necesidad de fondo, al menos sí por una razón cultural histórica: el fuerte calado que tiene en los países hispánicos la "tradición abúlica” (Subirats 110). Así como emergió esta tradición abúlica durante el cambio de siglo xix al xx bajo el signo del desastre, la degeneración o la decadencia de una España supuestamente imperiosa, parece volver a emerger durante el cambio de siglo xx al xxi bajo el signo de la degeneración, la decadencia o del desencanto, en esta ocasión, de un Estado Español (y una América Latina) subversivas que rechazan cualquier complicidad con los que mandan.

Bien sea de la mano de Max Nordau y Freud o bien de Lacan y Julia Kristeva, ambos fines de siglo tienden además a patologizar las crisis históricas y los conflictos ideológicos que estas crisis conllevan. En el caso del fin de siglo xix, el declive de una Europa racionalista que no pudo fundar las esperanzas que habían despertado las revoluciones liberales decimonónicas se transforma en "mal de siglo" (Cerezo, Mal 43); es decir, en "abulia, melancolía, acidia, ardor que no conduce a nada, sensualidad morbosa, indolencia que muerde la voluntad” (Villena 18). En el caso del fin de siglo xx y de España específicamente, la pérdida de "lo que pudiera haber sido el centro sagrado de una auténtica renovación” (Subirats 40) lo hace asimismo en "melancolía”, "tumor, "quiste canceroso" y otras tantas patologías culturales.

Por último, ambos fines de siglo acusan también casi a partes iguales un extremado individualismo. Cargado de un profundo criticismo social, durante el fin de siglo xix el individualismo se manifestó en esa cualidad ética y estética que Pedro Cerezo identifica, por ejemplo, en algunas obras de Miguel de Unamuno: el egotismo ("Variaciones" 66). Conforme se acerca el fin de siglo xx, por otro lado, el individualismo vuelve a protagonizar nuevamente buena parte de la literatura bajo la forma de un "narcisismo sentimental" que dice Mainer en De posguerra (153). Narcisismo sentimental, además, que puede ser detectable asimismo en el subjetivismo y, en ocasiones, autobiografismo explícito de la crítica cultural contemporánea. ${ }^{5}$

Según este orden de cosas, el malestar de la cultura de fin-de-siècle parece recurrir nuevamente dentro de España en la última década del siglo xx bajo estas otras dolencias de prognosis posfranquista. Que aquel fin de siècle decimonónico fuera clave en el

5 Ver a estos efectos mi ensayo "La imaginación desmadrada de Juan José Millás: humor y melancolía en La soledad era esto" y, más aún, el iluminador ensayo de Juan F. Egea acerca de la película de Jaima Chavarri El desencanto.

ISSN 0034-9631 (Impreso) 
impulso de la modernidad en España es hoy un tema bastante bien recibido aunque no por ello la cuestión esté ni mucho menos agotada. Que este último fin de siglo, por otra parte, siga o no incidiendo en la modernización de España es, a falta de perspectiva histórica, otro asunto aún más controvertido todavía. Lo cierto es que, como sucedió con los intelectuales del penúltimo cambio de siglo (Unamuno, Azorín, Baroja, Ortega y Gasset), la crítica en/de la posdictadura se está preguntando insistentemente también por "nuevas formas de incidencia operativa en el presente" (Richard, "Reconfiguraciones" 291). Lo que se necesita, insiste Nelly Richard, es responder a estas preguntas: “¿Cómo dar cuenta de lo que trastocó nuestras formas de vida y conocimiento [...] pero sin renunciar a la tarea de reformular conceptualmente a los significados de la experiencia? ¿Cómo articular una distancia reflexiva que se aleje del simple realismo testimonial de lo vivenciado afectivamente? ¿Cómo retramar articulaciones significantes y conexiones operativas para que el pensar crítico se active como tal?” (290). Frente a tales preguntas que suscita el "nuevo paradigma melancólico" (Medina) de fines de siglo xx, la misma historia cultural de la melancolía puede ofrecer, sostendré para concluir, si no respuestas claras, al menos sí posibles alternativas a toda esta tendencia tan paradigmáticamente finisecular de transformar el desahucio que dejaron las utopías en profundo malestar, lamentación, queja y desencanto.

\section{DESENCANTOS EJEMPLARES}

En el siglo xix, sobre todo durante su último tercio, el malestar político y afectivo que dejaron a su término las revoluciones liberales produjo en toda Europa un extraordinario bienestar literario. Irónicamente, aquel “mal de siglo” vino acompañado por una literatura simbolista, y, en general, un arte modernista que "se siente fin y se deleita en esa mórbida sensación de acabamiento", nos recuerda Luis Antonio de Villena (52) en referencia a una de las estéticas más interesantes del cambio de siglo xix a Xx. Desde Rubén Darío (Los raros) y antes Théophile Gautier y Charles Baudelaire, a Alejandro Sawa y Ramón del Valle-Inclán, pasando por el colombiano José Asunción Silva, el cubano Julián del Casal o el mexicano Efrén Rebolledo, escritores de raigambre fundamentalmente simbolista transformaron el entonces llamado "mal de siglo" en instancia crítica para la regeneración: en "apuesta”, sigue de Villena, "por una transformación, por un cambio en las costumbres y en la vida que nos llevaría -pocas veces ocurre-a un mundo nuevo, al que todo gran creador aspira" (54). ${ }^{6}$

A lo que podría plantearse, según lo argumentado arriba, como una reformulación contemporánea de aquel "mal de siglo" decimonónico parecen responderle también

6 Remito al libro Modernismo de Gutiérrez Girardot para una visión y documentación bibliográfica sobre esta corriente literaria de fin de siglo XIX.

\footnotetext{
Revista Iberoamericana, Vol. LXXX, Núm. 247, Abril-Junio 2014, 535-551 
durantela década de los noventa otras apuestas literarias no menos irónicas. La sublimación (en el sentido aquí de 'elevación') del desencanto, tan hegemónica dentro de las críticas posdictatoriales, debería caer en la cuenta de que en el humor -frecuentemente humor negro- la melancolía ha encontrado su razón de ser y acaso también su cura. Es cierto, como sostiene Vilarós, que la "banalidad", aglutinada en dictámenes del tipo "saber que ya nada importa nada" (Albiac), instituye desde los sesenta "el modo de circulación biopolítica en la era posmoderna” y la consiguiente “deshistorización”, “despolitización” y "desnarrativización” de la sociedad española ("Banalidad y biopolítica” 41). Pero no es menos cierto tampoco que, al menos en ciertas obras literarias (como sostiene Harvie Ferguson en relación a algunos escritores románticos), la complicidad de la melancolía con la ironía "is a token of its detachment from the world of actual events, and it is by adopting an ironic pose that the modern Romantic spirit seeks to preserve the full potentiality of the human" (39).

Hijos sin hijos (1993) de Enrique Vila-Matas, otro narrador como Félix de Azúa de aquella generación que llega al fin de siglo "desencantada” y "perdida”, es una novela ejemplar sobre ese potencial humano que puede encerrar el humor negro de la melancolía. Vila-Matas recuerda acontecimientos históricos de los últimos 41 años previos a la publicación de su novela mediante relatos protagonizados por personajes que carecen de descendencia o que reniegan de ella. El Mayo del 68, la muerte de Franco o la caída del Muro de Berlín coinciden en cada relato con actividades cotidianas o históricamente intrascendentes de hijos sin hijos. El día en que muere el dictador, por ejemplo, un preso político espera la Ley de Amnistía solo para reunirse luego en casa con el "endemoniado tirano” de su hijo de diez años, que fue quien desde recién nacido le amargó la vida hasta el extremo de conducirlo a realizar la locura que lo puso entre rejas. Al mismo tiempo que cae el Muro de Berlín, otra ironía ejemplar, un crítico literario ve alzarse dentro de su casa otro muro entre él y un amigo de infancia, escritor y soñador, que se le ha plantado en casa después de que el crítico retomara el contacto con él durante una escapada caprichosa a su tierra natal donde más vivos tuvo los deseos de transformar el mundo. Son ejemplos sumamente ilustrativos del poder literario de las ironías en tanto transforman la intrascendencia, la inutilidad y la banalidad de cada personaje en conciencia de sus respectivas limitaciones e indeterminaciones.

Historia de un idiota contada por él mismo (1986), del mismo Félix de Azúa de Demasiadas preguntas, da otra vuelta de tuerca a este potencial humano que puede encerrar el humor negro. Historia de un idiota narra la búsqueda suicida e infructuosa del "contenido de la felicidad" por parte de un personaje que simula, por muchas coincidencias solapadas entre la ficción relatada y la biografía del autor, al propio Azúa: el idiota auto-consciente. Al final de esta especie de "simulacro autobiográfico", el suicida incompleto termina sobreviviéndose a sí mismo: "Me consideraba", concluye sonriente el idiota, "un hombre LIBRE Y DESDICHADO [... . s sordo y ciego, pero con 
la capacidad de asombro intacta, como al comienzo, antes del primer tortazo. Pero YA NO ERA YO. No estaba muerto de un modo COMPLETO, pero había logrado matar la dependencia, la angustia que durante años me había destruido interiormente" (117-119).

No es tarea fácil entender la risa idiota y melancólica-¿̇la melancorrisa?- de este sujeto desencantado después de haber sufrido en carne propia duros desengaños. Pero tampoco creo que sea del género de los más idiotas querer preservar tal "potentiality of the human" (Ferguson 39), y no necesariamente aquí "too human”. Idiotas que sin embargo resultan sabios, como este personaje de Azúa; amnistiados que al salir de su cautiverio se descubren afuera más miserables y cautivos todavía que dentro de la cárcel, como ese preso político de Vila-Matas; modernos internacionalistas que al caer las fronteras y los muros se hallan enclaustrados en el más ingenuo y pueblerino de sus recreos de infancia, como aquel crítico literario del otro relato de Vila-Matas. Tal es la lección que nos deja la década de los noventa: la conciencia de la arbitrariedad del tiempo y de nuestras voluntades, incluidas las voluntades más arrebatadas, convencidas y esperanzadas. $\mathrm{O}$ con otras palabras, al cabo del siglo xx reconocemos nuevamente que "todo está expuesto a los mayores vuelcos -el revés del tiempo, su negra espalda" como escribe Javier Marías en una de las novelas finiseculares más importantes que han dado en España los años noventa:

[L]os hemos visto en la vida como en la novela y el teatro y el cine, escritores o sabios mendigos y reyes sin reino o esclavizados, príncipes encerrados en torres y asfixiados por una almohada, suicidados banqueros y beldades convertidas en monstruos tras ser arrasadas por vitriolo o por un cuchillo, nobles sumergidos en tinajas de nauseabundo vino e ídolos de las multitudes colgados de los pies como cerdos o arrastrados por un caballo, desertores convertidos en dioses y criminales en santos, ingenios reducidos a la condición de borrachos obstusos y tullidos coronados que seducen a las más hermosas sorteando su odio o aun transformándolo; y amantes que asesinan a quienes los aman. (244)

Deudores remotamente de la agudeza y el arte de ingenio de los Siglos de Oro, estos otros desencantos ejemplares del fin de siglo xx no son representativos sin embargo de la tradición hispánica exclusivamente. No pueden ser españoles ni posdictatoriales ni desencantados tales ejemplos literarios sin cuestionar, al mismo tiempo, esa tradición abúlica y española que, a tenor de lo dicho, caracteriza a los modos de análisis en clave posfranquista de la sociedad y la cultura española de los años noventa. Dentro de la tradición literaria española "de posguerra” (1951-1990 según Mainer), un desertor convertido en dios y un criminal en santo, un idiota vuelto sabio y un amnistiado, preso, suscitan, ante todo, extrañeza. Una extrañeza similar a la que producen en contrapartida los "postmodern paletos" a partir también de los noventas cuando, según Nathan E. Richardson, "the unified, homogenous Spain of the Franco years appears finally to have

\footnotetext{
Revista Iberoamericana, Vol. LXXX, Núm. 247, Abril-Junio 2014, 535-551 ISSN 0034-9631 (Impreso) ISSN 2154-4794 (Electrónico)
} 
been dismantled” (173). Tal extrañeza es tan española como teutona, tan trágica como ridícula, tan histórica y real como literaria e inventada. Y querer ver en esa extrañeza una alegoría de la melancolía posfranquista, pese a la profunda crítica política que encierra, es convertir la oportunidad de regeneración que concede todo desahucio en perpetuación de la abulia.

En otra explícita apuesta por la capacidad crítica de la literatura, Gerhard Hoffmann concluye su análisis de la narrativa contemporánea norteamericana destacando "the legacy of uncertainty that postmodern aesthetics left to the fiction of the final decade of the century” (203, énfasis mío). Mediante el análisis de novelas de los años noventa de Don DeLillo, John Updike, Philip Roth y Toni Morrison, Hoffmann invoca bajo la noción de lo grotesco toda una corriente artística de origen carnavalesco. Novelas como Underworld (DeLillo 1997), In the Beauty of the Lilies (Updike 1996), American Pastoral (Roth 1998) y Paradise (Morrison 1998) transforman el vacío o el desahucio norteamericano de los años noventa en "awareness of incompleteness" (210); es decir, en una conciencia de la realidad que al decir de Hoffman está "marked by mysteries, coincidences and strange events” (239).

Esta especie de compromiso con el azar, por oposición aquí al tradicional "compromiso con la causa", reconoce al mismo tiempo "the mystery of the void", en términos de Hoffman, así como "the mystery of regeneration” (203). (Recuérdese al respecto que tanto la tragedia como la comedia tuvieron su origen en rituales de fertilidad). El recalcado desencanto de los noventa mantiene así una compleja relación dialógica con la no menos recalcada utopía de los sesenta. No se trata solo de una "eliminación" de los viejos del 75 por los jóvenes de la Generación X, ni tampoco únicamente de la “acumulación” de ambas generaciones, volviendo aquí a la terminología de Ortega. Los noventa traen a la vez tanto una "alternativa al grupo de novelistas de la guerra.... a los novelistas de medio siglo y a los nuevos narradores de la transición” (De Urioste 457), como un reemplazo: "muggings of the mind replaced collective and public rioting" escribe por otra parte Tara Brabazon (13) en relación con las culturas jóvenes de los 1980 y 1990. Con otras palabras, el fin de siglo xx representa al mismo tiempo tanto el "cambio drástico y profundo" (Henseler y Pope xiv) con respecto a la España, y, en general, al mundo previos a 1989, como su contrapartida. Parafraseando a Brabazon, los años noventa son, en última instancia, "dialectically the other” de los sesenta (17); son la utopía y el desencanto, la expectativa y su decepción, la revolución y su revelación.

No por azar esa "ironía consciente" que al decir de Urioste (457) traen los noventa sale con especial mordacidad de escritores que han vivido ambas eras, los sesenta y los noventa, y que se han descubierto a fin de siglo ejemplarmente desencantados. Félix de Azúa, Vila-Matas y Javier Marías, entre otros, ofrecen ejemplos literarios de un tipo de risa melancólica que se ríe incluso de la "falsa conciencia" de los cínicos. Haciéndome eco de Peter Sloterdijk, la melancorrisa de esos escritores es la risa del

\footnotetext{
Revista Iberoamericana, Vol. LXXX, Núm. 247, Abril-Junio 2014, 535-551 ISSN 0034-9631 (Impreso) ISSN 2154-4794 (Electrónico)
} 
kinicism encarnado en Diógenes; es decir, de una “dialéctica de la desinhibición” (101), de una degeneración humorística o de una imaginación desmadrada que privilegia la sátira como forma de resistencia a los nuevos malestares de la cultura y que también afecta algunos escritores más jóvenes del cambio de siglo, como por ejemplo el José Ovejero de La comedia salvaje (2009). ${ }^{7}$

Peor sería no tener de qué desencantarse. Acaso por esta razón vengan en el siglo xxi a entusiasmar nuevamente las utopías, las ilusiones y hasta las revoluciones sociales. Quién sabe si para volver otra vez a descubrirnos solos o a reconocernos en esta frase de René Daumal que recordaba Julio Cortázar antes todavía de los sesenta, justamente en plena mitad del siglo xx: "Solos, después de acabar con la ilusión de no estar solos, no somos ya los únicos que estamos solos” (240).

\section{BiBLIOGRAFÍA}

Agawu-Kakraba, Yaw. Postmodernity in Spanish Fiction and Culture. Cardiff: U of Wales P, 2010.

Albiac, Gabriel. Mayo del 68: Una educación sentimental. Madrid: Temas de Hoy, 1993. Avelar, Idelber. The Untimely Present: Postdictatorial Latin American Fiction and the Task of Mourning. Durham: Duke UP, 1999.

Azúa, Félix. Demasiadas preguntas. Barcelona: Editorial Anagrama, 1994.

Historia de un idiota contada por él mismo, o, el contenido de la felicidad. Barcelona: Anagrama, 1986.

Bartra, Roger. Cultura y melancolía: las enfermedades del alma en la España del Siglo de Oro. Barcelona: Anagrama, 2001.

Beltrán, Luis. "Los sueños de la izquierda”. El Viejo Topo 136 (2000): 38-43.

Benjamin, Walter. "Left-Wing Melancholy (On Erich Kastner's New Book of Poems).” Screen 15/2 (1974): 28-32.

Bilbeny, Norbert. Aproximación a la ética. Barcelona: Ariel, 1992.

Brabazon, Tara. From Revolution to Revelation: Generation X, Popular Memory, and Cultural Studies. Burlington: Ashgate Publishing Company, 2005.

Brown, Wendy. Politics Out of History. Princeton: Princeton UP, 2001.

Buckley, Ramón. La doble transición. Política y literatura en la España de los años setenta. Madrid: Siglo XXI de España, 1996.

Carr, Raymond. Modern Spain, 1875-1980. Oxford: Oxford UP, 1980. Visiones De Fin De Siglo. Madrid: Taurus, 1999.

\footnotetext{
7 Una conclusión similar a esta apuesta por la risa extrae Luis Beltrán cuando en el año 2000 responde a la cuestión ¿con qué sueña la izquierda hoy? También ahí su concepto de la risa trata de diferenciarse de la risa individualista y cínica en beneficio más bien de una risa popular y carnavalesca.
}

ISSN 0034-9631 (Impreso) 
y Juan Pablo Fusi Aizpurua. Spain: Dictatorship to Democracy. Londres: Harper Collins Academic, 1981.

Castellet, J. M. Nueve novísimos poetas españoles. Barcelona: Barral, 1970.

Cerezo, Pedro. El mal del siglo: el conflicto entre Ilustración y Romanticismo en la crisis finisecular del siglo XIX. Madrid: Biblioteca Nueva, 2003.

"Variaciones sobre el tema del yo en la crisis de fin de siglo". Tu mano es mi destino. Salamanca: Ediciones U. Salamanca (2000): 59-82.

Cortázar, Julio. “Situación de la novela(1950)”. Obra crítica/2. Madrid:Alfaguara, 1994.

Dahrendorf, Ralf. After 1989: Morals, Revolution and Civil Society. Basingstoke: Macmillan in association with St Antony's College Oxford, 1997.

Egea, Juan. “El desencanto: la mirada del padre y las lecturas de la transición”. Symposium 582/2 (2004): 79-92.

Encinar, Angeles y Kathleen M. Glenn, eds. La pluralidad narrativa: escritores españoles contemporáneos (1984-2004). Madrid: Biblioteca Nueva, 2005.

Epps, Bradley. "Questioning the Text." The Cambridge Companion to the Spanish Novel from 1600 to the Present. Harriet Turner y Adelaide López de Martínez, eds. Cambridge: Cambridge UP, 2003. 193-211.

Ferguson, Harvie. Melancholy and the Critique of Modernity: Søren Kierkegaard's Religious Psychology. Londres: Routledge, 1995.

Flórez Miguel, Cirilo. Tu mano es mi destino. Salamanca: Ediciones Universidad de Salamanca, 2000.

Freud, Sigmund. "La aflicción y la melancolía”. El malestar de la cultura. Madrid: Alianza, 2001. 231-248.

Graham, Helen, y Jo Labanyi. Spanish Cultural Studies: An Introduction: The Struggle for Modernity. Oxford: Oxford UP, 1995.

Gutiérrez Girardot, Rafael. Modernismo. Barcelona: Montesinos, 1983.

Gutiérrez-Mouat, Ricardo. "Postdictadura y crítica cultural trasatlántica”. Revista Iberoamericana (2006): 33-150.

Henseler, Christine y Randolph d. Pope. "Generation X and Rock: The Sounds of a New Tradition.” Generation X rocks. Contemporary Peninsular Fiction, Film, and Rock Culture. Christine Henseler y Randolph D. Pope, eds. Nashville: Vanderbilt UP, 2007. xi-xxiii.

Hoffman, Gerhard. Postmodernism and the Fin de Siècle. Heidelberg: Winter, 2002. "The Aesthetics of the Mysterious and the Grotesque in the American Novel of the Nineties.” Postmodernism and the Fin de Siècle. Heidelberg: Winter, 2002. 203-240. Hoffmann, Gerhard. Postmodernism and the Fin de Siècle. Heidelberg: Winter, 2002. Jáuregui, Carlos y Juan Pablo Dabove, eds. Heterotopías: Narrativas de identidad y alteridad latinoamericana. Pittsburgh: Instituto Internacional de Literatura Iberoamericana, 2003.

\footnotetext{
Revista Iberoamericana, Vol. LXXX, Núm. 247, Abril-Junio 2014, 535-551 ISSN 0034-9631 (Impreso) ISSN 2154-4794 (Electrónico)
} 
Juliá, Santos y Paloma Aguilar. Memoria de la guerra civil y del franquismo. Madrid: Taurus, 2006.

Kleist, Jürgen. Preface. Fin de siècle. 19th and 20th Century Comparisons and Perspectives. Jürgen Kleist y Bruce A. Butterfield, eds. Nueva York: Peter Lang, 1996. ix-xiii.

Kristeva, Julia. BlackSun: Depression and Melancholia. Nueva York: Columbia UP, 1989.

Loureiro, Ángel. “Argumentos patéticos. Historia y memoria de la Guerra Civil”. Claves de Razón Práctica 186 (2008): 18-25.

Magris, Claudio. Utopía y desencanto: Historias, esperanzas e ilusiones de la modernidad. Barcelona: Anagrama, 2001.

Mainer, José Carlos. De Postguerra (1951-1990). Barcelona: Crítica, 1994.

“El Problema de las generaciones en la literatura española contemporánea”. Actas de la Asociación Internacional de Hispanistas (1971): 211-219.

Marías, Javier. Mañana en la batalla piensa en mí. Madrid: Alfaguara, 1996.

Marina, José Antonio. Ética para náufragos. Barcelona: Anagrama, 1995.

Medina Domínguez, Alberto. Exorcismos de la memoria: políticas y poéticas de la melancolía en la España de la transición. Madrid: Libertarias, 2001.

Mínguez-Arranz, Norberto. Literatura española y cine. Madrid: Complutense, 2002.

Morales-Rivera, Santiago. "Degeneration of the Sixties. A Look at Spain”. ReVista: Harvard Review of Latin America VII/17 (Winter 2009): 39-42.

"La imaginación desmadrada de Juan José Millás: humor y melancolía en La soledad era esto”. Revista hispánica moderna 64/2 (2011): 129-148.

Moreiras Menor, Cristina. Cultura herida: Literatura y cine en la España democrática. Madrid: Libertarias, 2002.

Muguerza, Javier. Desde la perplejidad: ensayo sobre la razón, la ética y el diálogo. Madrid: FCE, 1990.

Nordau, Max. Degeneration. Londres: Gardners Books, 2007.

Odartey-Wellington, Dorothy. Contemporary Spanish Fiction: Generation X. Newark: U of Delware P, 2008.

Ovejero, José. La comedia salvaje. Madrid: Alfaguara, 2009.

Ortega y Gasset, José. El tema de nuestro tiempo. Madrid: Revista de Occidente, 1981.

París, Carlos. Unamuno: estructura de sumundo intelectual. Barcelona:Anthropos, 1989.

Payne, Stanley. The Franco Regime, 1936-1975. Madison: U of Wisconsin P, 1987.

Pedrós-Gascón, Antonio Francisco. "Héroes para un nuevo 98 (acerca de una invisibilidad ideológica en la novela española reciente)”. España Contemporánea XXII/1 (Primavera 2009): 7-34.

Richard, Nelly. "Las Reconfiguraciones del pensamiento crítico en la posdictadura." Heterotropías: narrativas de identidad y alteridad latinoamericana. Pittsburgh: Biblioteca de América, 2003. 287-302.

Pensar en la postdictadura. Santiago de Chile: Cuarto Propio, 2001.

Revista Iberoamericana, Vol. LXXX, Núm. 247, Abril-Junio 2014, $535-551$
ISSN 0034-9631 (Impreso) 
Richardson, Nathan E. Postmodern Paletos. Inmigration, Democracy and Globalization in Spanish Narrative and Film (1950-2000). Lewisburg: Bucknell UP, 2002.

Savater, Fernando. Ética para Amador. Barcelona: Ariel, 2000.

La voluntad disculpada: Nihilismo y acción, La filosofia tachada, De los dioses y del mundo, La tarea del héroe. Madrid: Taurus, 1996.

Sloterdijk, Peter. Critique of Cynical Reason. Minneapolis: U of Minnesota P, 1987.

Subirats, Eduardo. Después de la lluvia: Sobre la ambigua modernidad española. Madrid: Temas de Hoy, 1993.

Turner, Harriet S., and Adelaida López de Martínez. The Cambridge Companion to the Spanish Novel: From 1600 to the Present. Cambridge: Cambridge UP, 2003.

Urioste, Carmen de. "La narrativa española de los noventa: ¿Existe una 'generación X’?” Letras Peninsulares 10/3 (1997): 455-476.

Vila-Matas, Enrique. Hijos sin hijos. Barcelona: Anagrama, 1993.

Vilarós, Teresa. "Cine y literatura en la España de los sesenta: Testimonio de un primer proceso de desideologización.” Literatura española y cine. Norberto Mínguez, ed. Madrid: Complutense, 2002. 193-206.

El mono del desencanto: una crítica cultural de la transición española (19731993). Madrid: Siglo XXI, 1998.

"Línea de fuerza. Banalidad y biopolítica: la transición española y el nuevo orden del mundo". Desacuerdos 2 (2005): 31-56.

Villena, Luis. Diccionario esencial del fin de siglo. Madrid: Valdemar, 2001.

Revista Iberoamericana, Vol. LXXX, Núm. 247, Abril-Junio 2014, $535-551$
ISSN 0034-9631 (Impreso) 
